\title{
Impact conditions of motorcyclist per body segment
}

\author{
AUTHORS \\ Nicolas Bourdet ${ }^{1}$, Oscar Cherta Ballestster ${ }^{2,3}$, Caroline Deck ${ }^{1}$, Frank Meyer ${ }^{1}$, Remy Willinger $^{1}$ \\ Affiliation: $\quad{ }^{1}$ University Strasbourg, Strasbourg France \\ ${ }^{2}$ Aix-Marseille Univ, Univ Gustave Eiffel, LBA, Marseille, France \\ ${ }^{3}$ IN\&MOTION S.A.S., Parc Altaïs, Chavanod, France
}

E-Mail: nicolas.bourdet@unistra.fr

\begin{abstract}
:
Multy-body simulation is applied to compute the motorcyclist's kinematic in case of virtual motorcycle versus car accident. Results show that for over $50 \%$ of the simulations, the impact velocities of the whole body exceed $8 \mathrm{~m} / \mathrm{s}$ when impacting the vehicle and $4 \mathrm{~m} / \mathrm{s}$ at the time of road impact. The head impacts the vehicle most often with a speed exceeding $7.5 \mathrm{~m} / \mathrm{s}$ on the fronto-lateral impact configuration, when thorax, abdomen and pelvis are the most exposed segments for the other impact configurations, with impact velocities beeing in the range of 10 to $15 \mathrm{~m} / \mathrm{s}$. Changes in BMI leads to minor influence on the impact velocities of the different body, especially for the first impact. As expected, body impact speed increases with the speed of the motorcycle, for both, the first and the second impacts. These results will contribute to an improvement in the evaluation and optimization of motorcyclist's protection garnement.
\end{abstract}

\section{Introduction}

Powered Two Wheelers (PTWs), i.e. mopeds and motorcycles, remains one of the most dangerous means of travel on today's roads. According to European safety Council shows that in 2015-2017 the $19 \%$ of road deaths were motorcyclists [1]. In USA, according to NHTSA (National Highway Traffic Safety Administration)'s report it appears that motorcyclists experience a 34-fold higher risk of death per vehicle-miles travelled than people driving other types of motor vehicles. According to NHTSA, 5,337 motorcyclists died in 2017. In EU, the number of fatalities and injuries in motorcycle accidents have not decreased since 1995, whereas the motorcycle park in circulation doubled during the same period [1]. Motorcyclists have the highest risk of being killed as occupant (driver or passenger) based on mileage, which is approximately 24.5 times higher than for passengers of light vehicles. In 2009, motorcyclists' deaths accounted for $20.8 \%$ of traffic fatalities. The mortality in PTW accidents was higher in the open countryside than in urban areas. In France, more than one in four are aged 25 to 34 (29.1\%) and more than half of the motorcyclists killed are under 35 (53.5\%) ONISR [2]. In Germany, Otte et al [3] analyzed 2199 motorcyclists accidents contained in the GIDAS database (1999-2008) concluding that $65 \%$ of the motorcyclists sustained minor injuries, while $9 \%$ were severely injured. They showed that injury severity depends on the relative speed of the vehicle. Until $30 \mathrm{~km} / \mathrm{h}$ the percentage of MAIS4+ victims was $0.9 \%$, whereas with a speed up to $70 \mathrm{~km} / \mathrm{h}$ the percentage increased to $8 \%$.

In contrast to car occupants, all body regions of motorcyclists are exposed to impacts when involved in an accident because of their relative lack of protection. Some authors such as Newmann [4], Rogers et al [5] and Serre et al [6] reported that motorcycle riders often sustain multiple injuries in a crash. The body regions most frequently injured are the upper and lower extremities, while the most severe injuries are located on the head, the neck and the thorax. In this context, increasing the performance of safety systems remains a priority for injury mitigation. The assessment and improvement of passive and active personal protection equipment (PPE) require the development of new testing methods 
based on the most relevant accident scenarios, the human body kinematics during these accidents and the mechanisms causing the injuries on the body regions of interest.

Because of the difficulty of realistic kinematic estimation from real-world accidents and the economic costs of performing crash tests, numerical or virtual accident simulations have been carried out in previous research to analyze motorcyclists' kinematics during accident situations. Some studies focused on head impacts [7], while other analyzed the impact conditions of the torso [8] to provide critical information for the evaluation of helmets and wearable airbag protectors effectiveness. The objective of the present study is to define realistic impact conditions for all human body segments in a range of typical PTW accident scenarios for the safety assessment and optimization of current protectors and the development of a new generation of protective systems. Indeed, the results will contribute to improving knowledge for the development of test methods for the evaluation of Personal Protective Equipment (PPE). They will make it possible to define specifications, particularly in terms of impact speed for each use case and body region. These will serve as baseline to define an assessment for the protective systems for each of the selected body regions, particularly head, thorax, abdomen and pelvis.

\section{Methods:}

Based on the real accident configurations collected in the French project Secu2RM and published by Cherta Ballester et al [8] in 2019, the present study proposes a parametric study to evaluate the impacts sustained by each body segment in terms of impact location, impact velocity and impact time for a single motorcyclist in accident configurations against a car.

The parametric study considered 2 types of PTW, 3 rider morphologies, 8 accident configurations and 2 PTW impact speeds leading to 96 accident situations as illustrated in Figure 1 . The first impact on the vehicle and the second impact on the road have been considered and differentiated.

The PTW models represent two main motorcycle types collected in the database, i.e. a sport motorcycle (Triumph Street triple) and a scooter (Piaggio Liberty). The type of vehicle retained for this study is a GeoMetro urban car because it represents a generic model of a small vehicle.

Three Body Mass Indexes (BMI) were defined corresponding to the 5th, 50th and 95th percentiles of the real accident victims observed. The 50th percentile male human model $(176 \mathrm{~cm}, 77 \mathrm{~kg})$ was modified to obtain three rider morphologies with BMIs of 19, 24 and 32 with a constant height of 176 $\mathrm{cm}$, using the GEBOD program implemented in Madymo ${ }^{\circledR}$ software, [9], [10].

Eight accident scenarios were chosen to simulate collisions of the front part of the motorcycle against several points of the car, as illustrated in Figure 1. Among them, 2 impacts to the front (head-on and oblique-on-front), 5 to the side ( 3 oblique-on-side and 2 head-on-side) and 1 to the rear (head-on-rear) of the car were reproduced.

Finally, two impact speeds for the PTW (50 and $70 \mathrm{~km} / \mathrm{h}$ ) were considered according to the accidents collected in the database (Cherta Ballester et al [8]) whose occurrence was often in a rural area. For all the simulations in this study, the initial speed of the car was $15 \mathrm{~km} / \mathrm{h}$, considering that the vehicle was maneuvering at a crossing. All these scenarios constitute a wide range of configuration of impact of the motorcycle on the car. The side-on-head impacts are not considered in this study. 


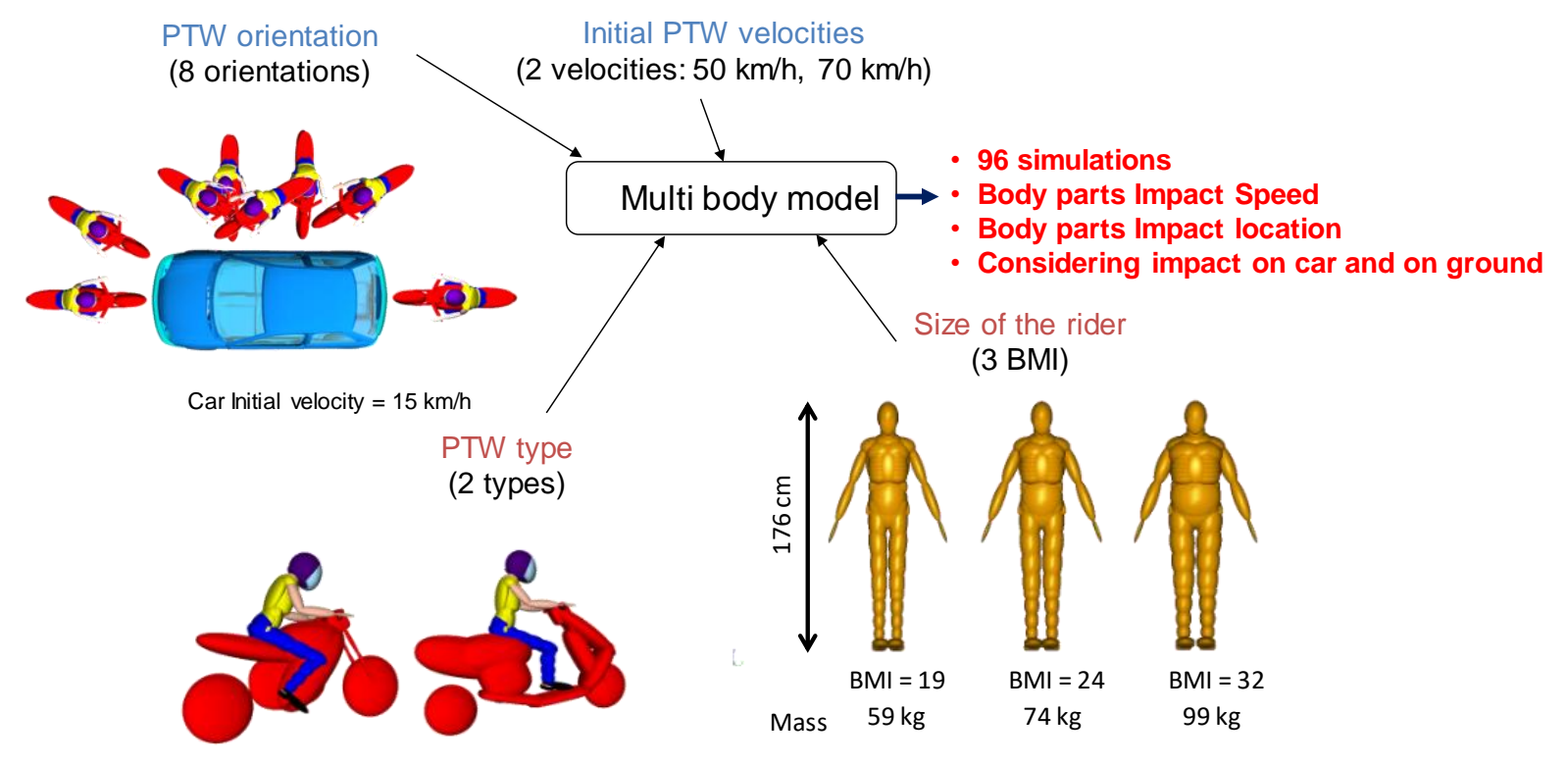

Figure 1. Illustration of the parametric study on PTW vs car accidents, leading to 96 accident configurations.

The accident simulations have been carried out using Madymo ${ }^{\circledR}$ software and output data are obtained and analyzed using a special designed program, allowing to extract the impact location of each body part as well as the velocity vector. The principle of solving a multibody system is to define a set of rigid bodies represented by ellipsoids and connected by joints. Contrary to finite element computation, contact between two bodies is computed by a penetration force defined by a function. The computational time of this multi-body approach is strongly reduced compared to finite element simulation.

The multi-body model representing the motorcyclist is the TNO adult human model implemented in the software. The model's dynamic behaviour was validated against post-mortem human tests, as reported by Van Hoof et al. [11] and De Lange et al. [12]. This human model was scalable using the GEBOD program implemented the Madymo ${ }^{\circledR}$ package [9], [13]. A helmet geometry was added to the human model composed of three ellipsoids representing the outer, the visor and the based. The contact force curve used come from experimental tests on a mean full-face motorcycle helmet carried out in laboratory.

The geometries of PTW and car models were developed superimposing the ellipsoids versus the CAD as illustrated in Figure 2. The mass and inertia of all the different parts of the vehicles are gathered from the datasheet available. The contact force functions used on each part of the car are extracted Martinez et al. [14], similarly as Bourdet et al. [15], [16].


Figure 2. Illustration of Car and PTWs models when superimposing ellipsoids and vehicles CAD geometry. 
Coming to the simulation output data, motorcyclist's impact location and impact time were considered as well as the velocity vector of the different body segments at the instant just before impact and called impact velocity. The impact time was computed as the period of time between the first contact of the PTW against the car and the first contact of the human body with the car and with the ground. A Python script was used to extract the impact conditions of the six body segments of interest (head, thorax, upper limbs, abdomen, pelvis and lower limbs) against the car and the ground, in terms of vector velocities, impact location on the body segment. Therefore, for each simulation the contact time of each body segment was extracted from the computed contact force curve where the force is zero as illustrated in Figure 3. The location of the impact point is then determined at this time step in terms of square zone of $20 \mathrm{~mm}$ large constituting of 25 pixels, as illustrated in Figure 3. Each pixel was added of one unit when contact exist. Thus, when an area was impacted several times, the pixels constituting of this area see theirs number of units increase and permits to propose a colormap to show the contact density. A mean value of body part impact velocity is computed in the same manner.

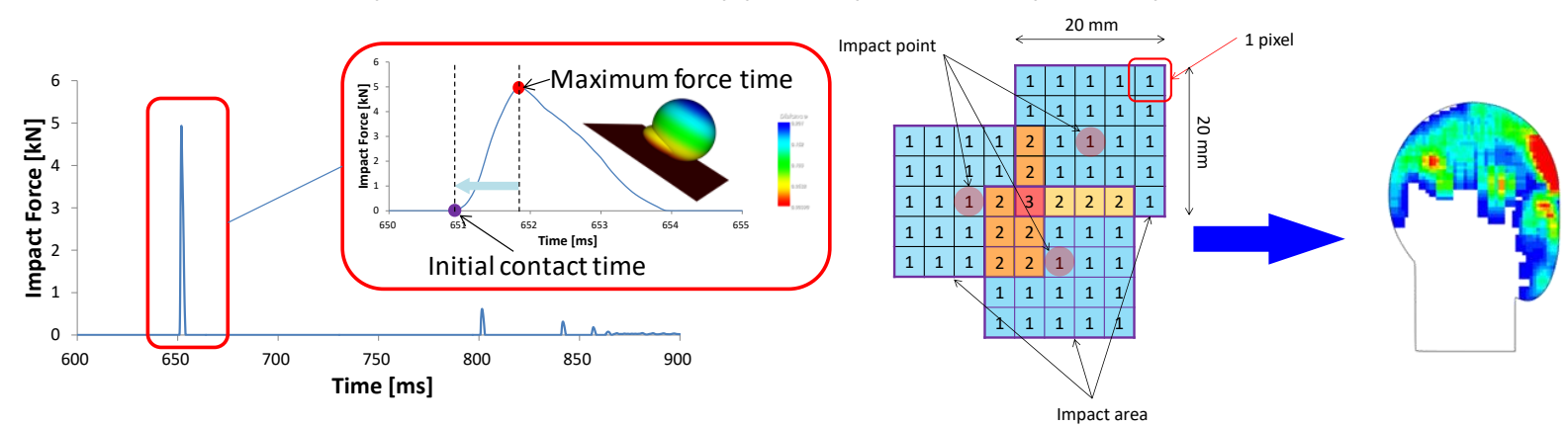

Figure 3. Determination of contact points converted in contact density.

\section{Results:}

A total of 96 PTW accident situations were simulated by multibody models and the impact conditions of the motorcyclist were analysed considering the first impact on the vehicle and the second impact on the road. Thus, a total of 1068 impacts human-car and 845 impacts human-road were detected using the algorithm described above, considering that body segments impact several times. The number of impacts was divided into six body zones (head, thorax, abdomen pelvis upper and lower limbs segments), as illustrated in Figure 4. It can be observed that lower limbs are the most often impacted parts followed by upper limbs. Figure 5 shows examples of rider kinematics for different configurations in which the body parts impact the vehicle and the ground.

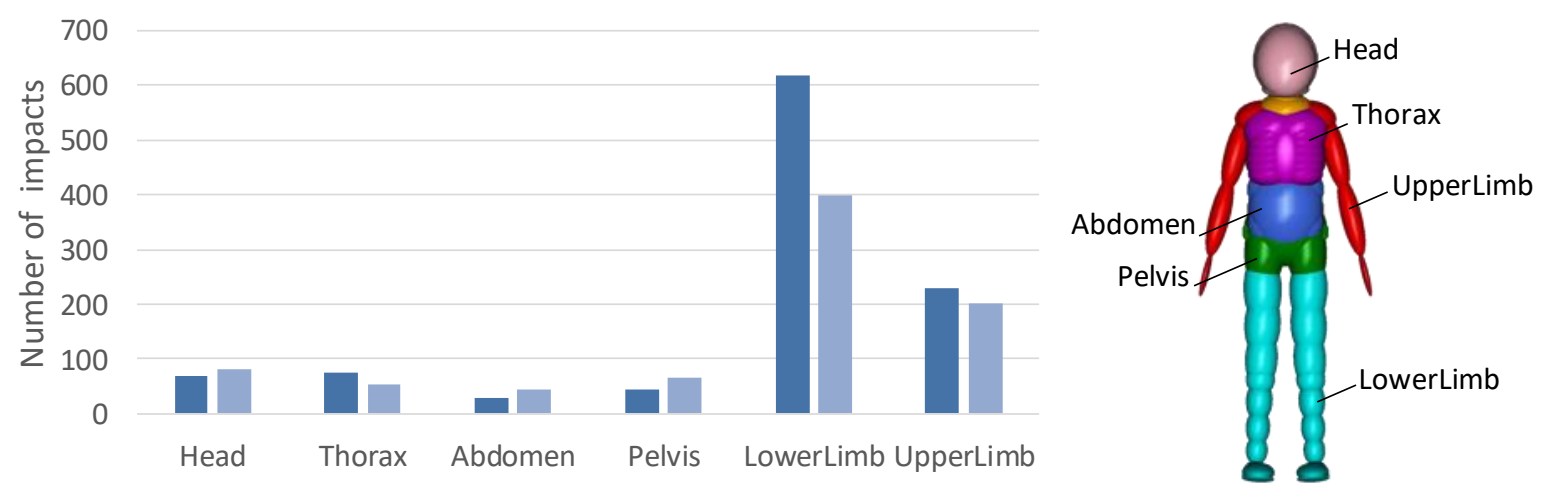

Figure 4. (on left) Number of body impacts on the vehicle (dark) and on the ground (light) considering lower and upper limbs. (on right) Discretization of the body zones. 


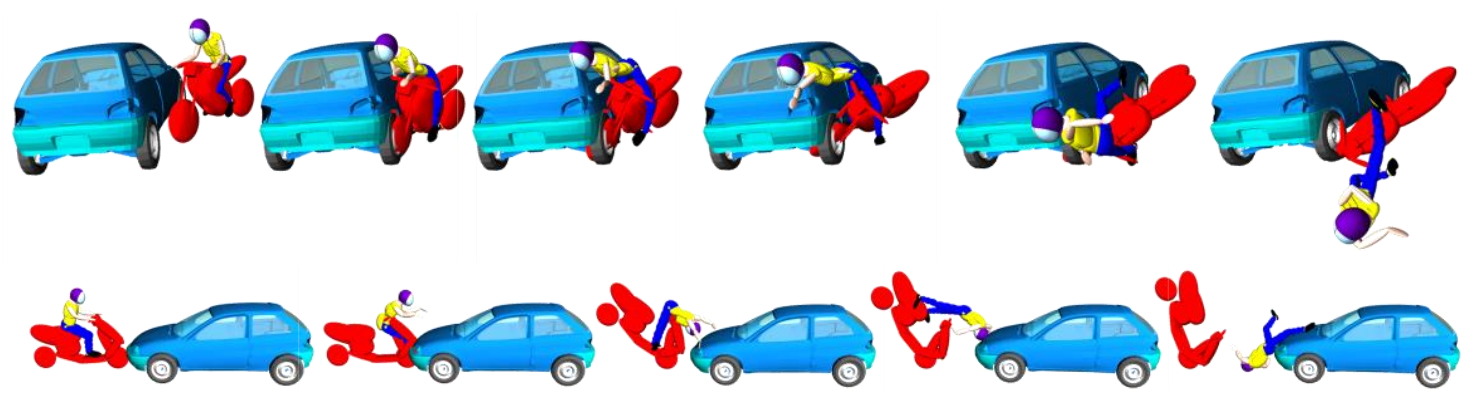

Figure 5. Examples of accident simulation kinematics.

\section{Impact location and velocity:}

Figure 6 and Figure 7 show the distribution of the contact points on the motorcyclists, in terms of density of contacts for the different impacts and in terms of resultant impact velocity for the different body parts and for all of the 96 simulations: Concerning the contact density, the red areas represent the most often impacted regions whereas the blue ones represent the less often impacted area. It is observed that the most often impacted area when impacting the vehicle are the face, the thorax (sternum) and the shoulder as well as the lower and upper limbs, with an impact velocity ranging from $8 \mathrm{~m} / \mathrm{s}$ to $16 \mathrm{~m} / \mathrm{s}$ (green and red colours). The body areas not impacted were let in white. On the other hand, when it comes to the ground impact, the distribution is more spread out and no strong predominance is observed. Interestingly, it appears that, the impact velocity is lower for this so-called second impact.
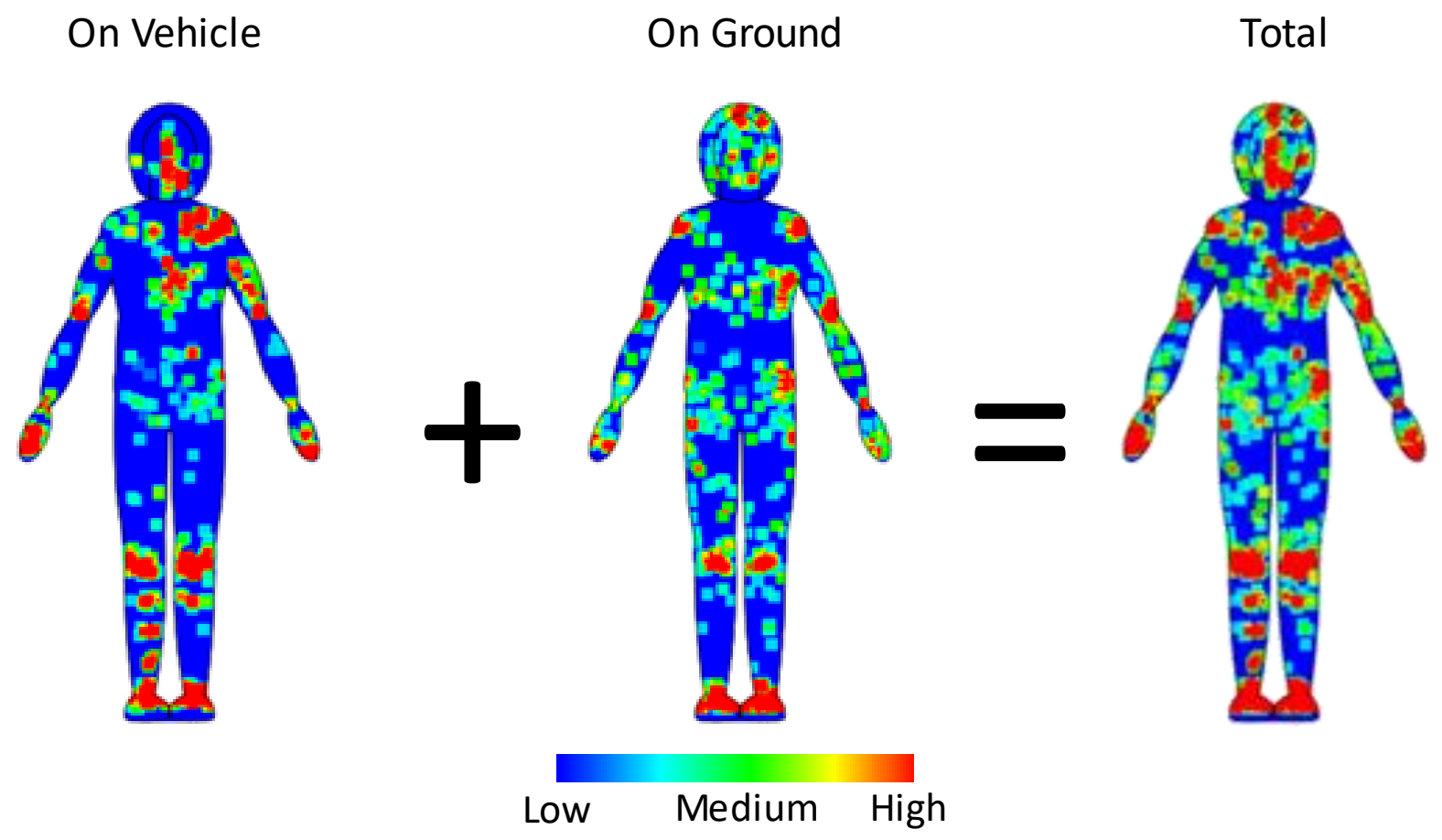

Figure 6. Distribution of the contact points on the whole body for all simulations combined in terms of density for the 96 accident configurations. 

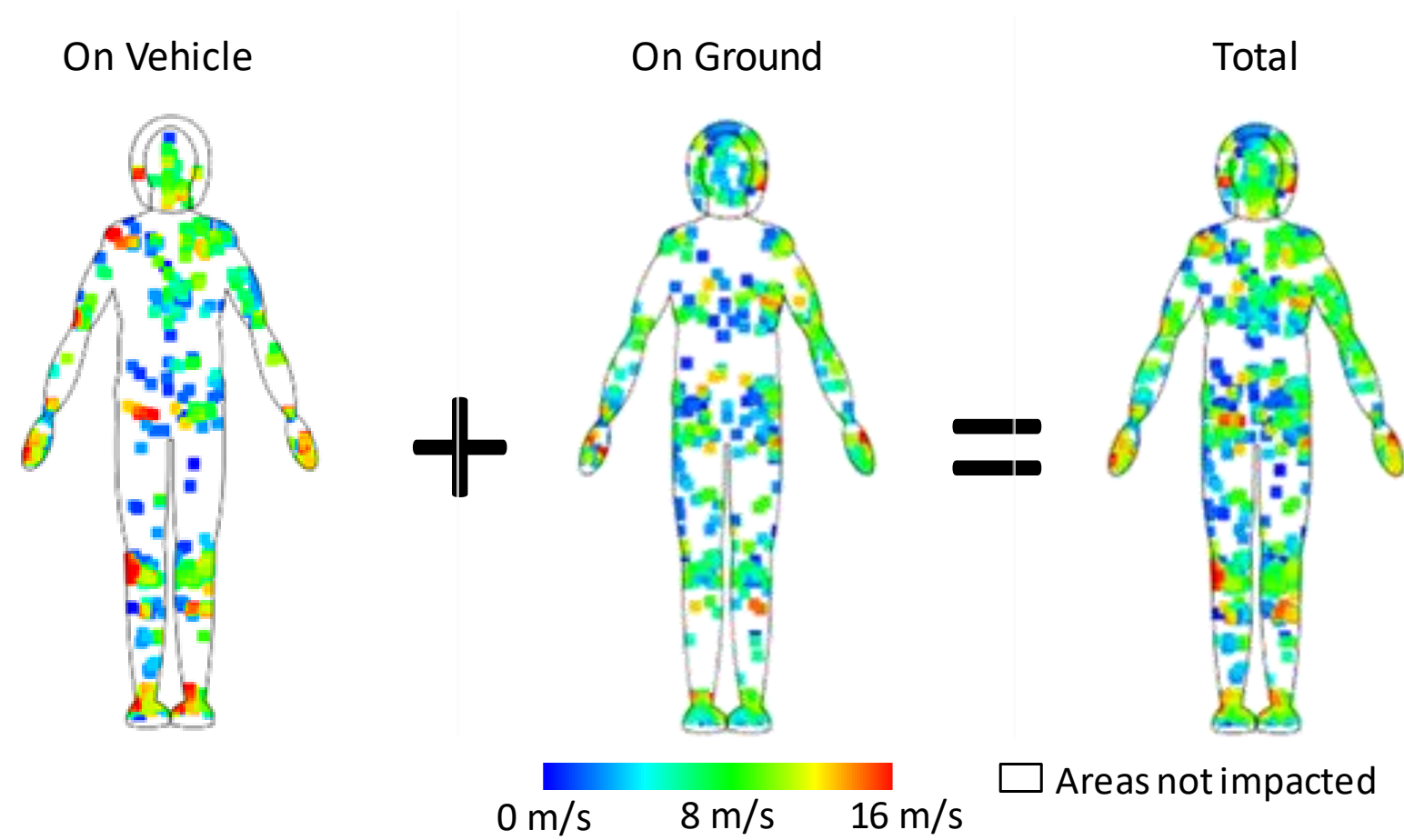

Figure 7. Distribution of the contact points on the whole body for all simulations combined in terms of resultant impact velocity for the 96 accident configurations.

The distributions of the contact point density on the whole body for the different simulations according to the accident scenario, the BMI and PTW initial velocity and type are illustrated separately in Figure 8. It can be observed that the accident scenarios distribute differently the impact points especially under oblique impact in which the localisation of the contact on the body human is lateral for both contact surface vehicle and ground. Concerning the BMI and PTW speed parameters, the impacts points are located similarly with almost same density by comparing each configuration according to the contact surface. With regard to the PTW type, a difference can be observed between motorcycle and scooter when impacting the vehicle. For the motorcycle, the impact points are more located on the sternum and middle of the upper thorax, whereas for scooter-pilot, sternum is weakly impacted. 

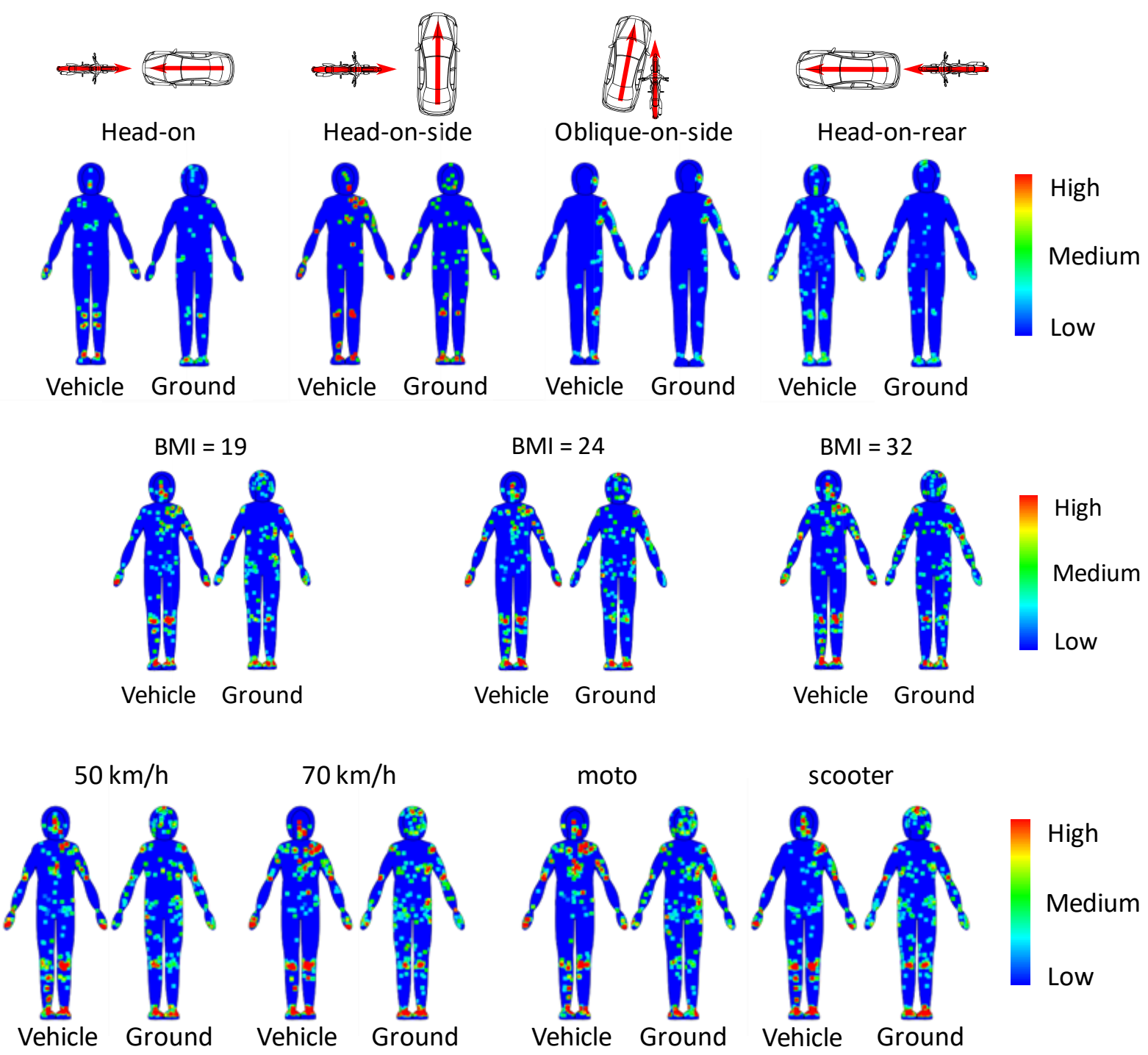

Figure 8. Distribution of the density contact points on the whole body separately for the different simulations according to the accident scenario (on top), the BMI (on middle) and PTW initial velocity and type (on bottom).

The impact velocity distribution for each body part based on the vehicle and ground impact configurations respectively are shown in Figure 9 . For the head, it is clearly observed that in $100 \%$ of reconstructed cases, the impact velocity is greater than $9.3 \mathrm{~m} / \mathrm{s}$ in head-on-side (HOS) configuration. For all other configurations except head-on $(\mathrm{HO})$, the head impact velocities are between 8 to $13 \mathrm{~m} / \mathrm{s}$ for $50 \%$ of the simulations when the head impacts the vehicle. On the other hand, the head impact velocity doesn't exceed $5 \mathrm{~m} / \mathrm{s}$ when it contacts the ground for $75 \%$ of the simulations. With regard to the thorax, in $50 \%$ of the cases, the impact velocity is greater than $8 \mathrm{~m} / \mathrm{s}$ in all configurations excepted in head-on (HO) impact. When impacting the ground, the impact configuration in which the highest impact speeds are observed is the oblique configuration for all parts of the body with a value of about $10 \mathrm{~m} / \mathrm{s}$. In the other configurations, more than $75 \%$ of the simulations show an impact speed below 5 $\mathrm{m} / \mathrm{s}$ for all the body parts.

The selected Body Mass Index (BMI) don't show any effect on the impact speeds of the different body parts, especially during contact on the car except concerning the pelvis. Indeed, the impact speed is over $6 \mathrm{~m} / \mathrm{s}$ in $75 \%$ of the simulations for a BMI 24 against below $6 \mathrm{~m} / \mathrm{s}$ in $75 \%$ of the simulations for a BMI 32. The influence of this parameter is more important on thorax for the ground impact. 
The speed of the PTW shows clearly an influence on the impact velocity of the head, thorax and abdomen, especially when there is contact on the vehicle. The mean velocity increases by about $5 \mathrm{~m} / \mathrm{s}$ with a raise of $20 \mathrm{~km} / \mathrm{h}(5.5 \mathrm{~m} / \mathrm{s})$ of the PTW speed. When impacting the ground, this raise can be observed only on the thorax. Pelvis velocity impact is weakly affected by this parameter.

For head and thorax, the computed impact velocities are higher for the moto rider than for the scooter rider, unlike for the abdomen. For pelvis, the results show that the impact velocity is higher by using a scooter when impacting the vehicle. For all body parts, the distributions of the impact velocities are more spread out with the scooter.

a)

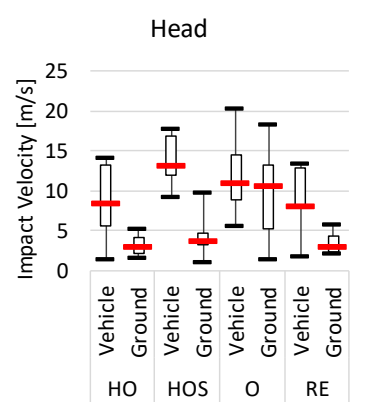

b)

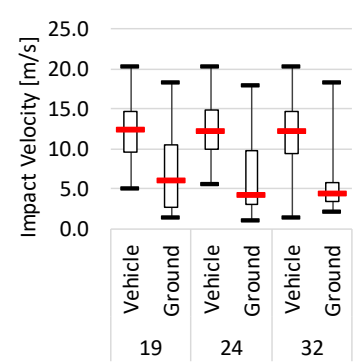

c)

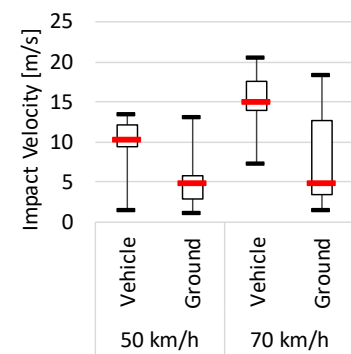

d)

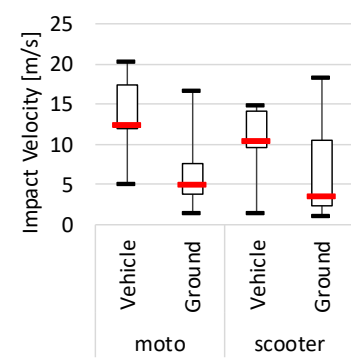

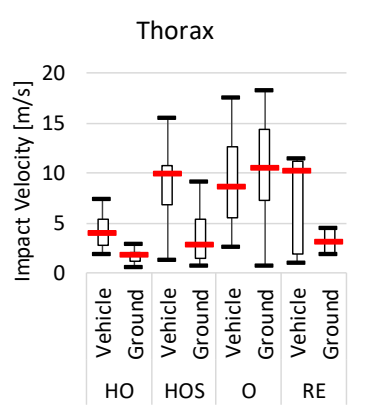


Abdomen
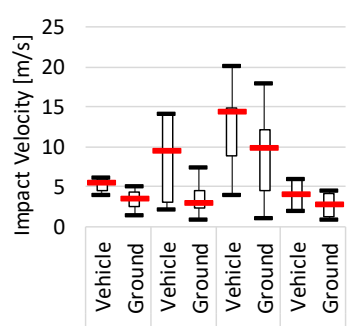

HO HOS O RE
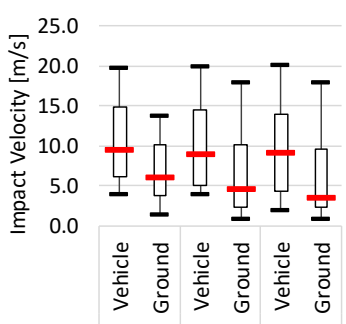

\begin{tabular}{|l|l|l|}
\hline 19 & 24 & 32 \\
\hline
\end{tabular}
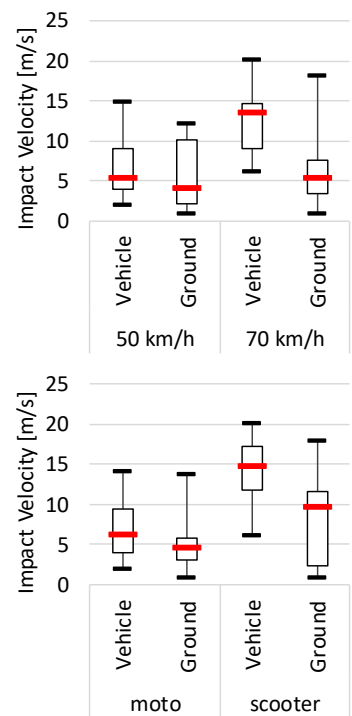

Pelvis
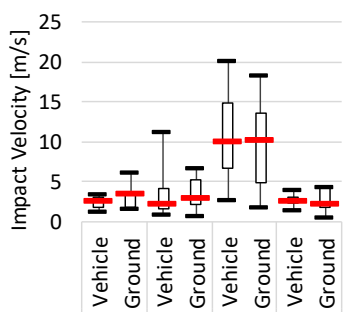
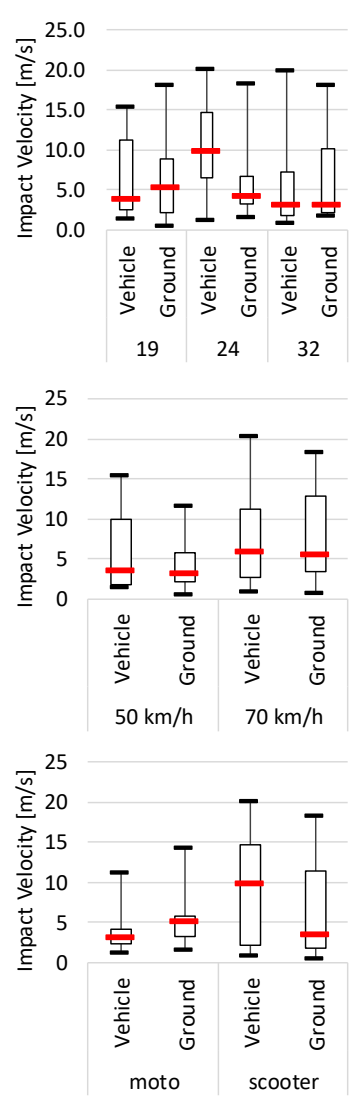

Figure 9. Boxplot of human segments' impact velocity distribution when impacting the vehicle and the ground according to the accident scenario Head-On (HO), Head-On-Side (HOS), Oblique-On-Side (OOS) and Head-on-rear (HOR)(a), BMI (b), PTW velocity (c) and PTW type $(d)$.

\section{Impact time:}

Figure 10 shows the cumulative frequency of the time when body parts come into contact with the car and the ground appear. The median time, i.e. the time for $50 \%$ of the virtual accident simulations, was 
extracted for each segments. It was also shown that the car impact occurs typically 80 to $100 \mathrm{~ms}$ after the first motorcycle to car contact, when the timing of the second impact ranges from 800 to $1000 \mathrm{~ms}$.
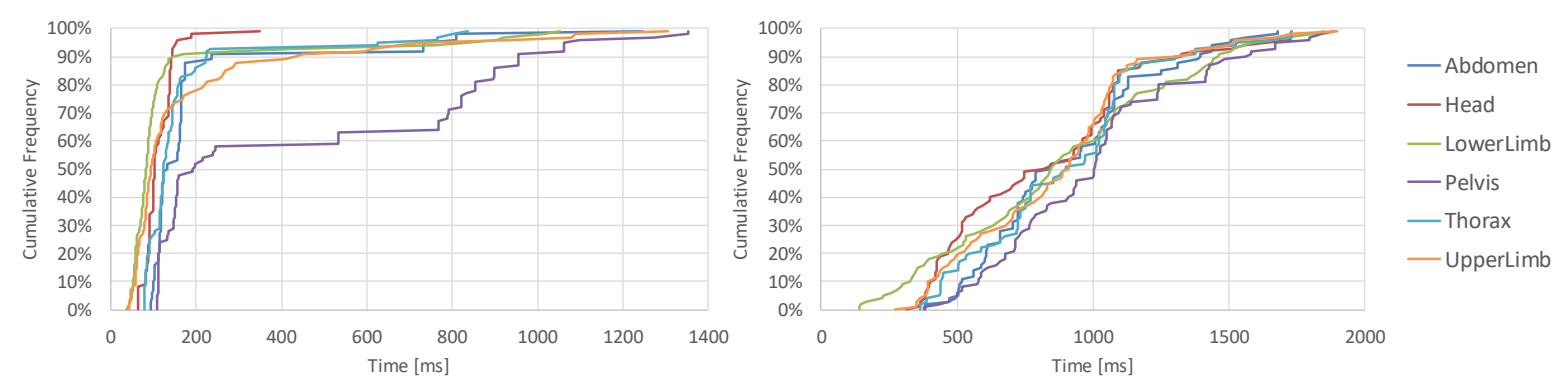

Figure 10. Representation of the cumulative frequency of the time when the contact of the parts of the body on the car (on left) and (on road) appear.

\section{Discussion}

A parametric study was performed based on multibody simulation inspired from real world accident data to provide a range of realistic motorcyclist's impact conditions for the assessment of safety devices. Due to the endless number of different motorcycle accident situations in real life, this work focused on the simulation of a set of typical PTW accident scenarios. It considered two types of PTW, three rider morphologies, eight accident scenarios and two PTW impact velocities. All these parameters were defined according to the SECU2RM French database that contains victims admitted into the shock rooms of two French trauma centres [8]. Considering the chosen accident scenarios, similar accident configurations were observed in COST 327 [17] and Piantini et al [7], [18]. The impact speeds are coherent with those recorded in the study of Piantini et al [7].

The analysis of the impacts sustained by the motorcyclist showed that the thorax and lower limbs are the most frequently impacted parts of the human body in the simulated accident scenarios. These results are in line with the epidemiological studies reported by Fredriksson and Sui in 2016 [19] and Otte et al in 2018 [3] where $47.7 \%$ of the AIS3+ victims were injured on the thorax and $44.3 \%$ on the lower limbs. Moskal et al in 2007 [20] described injuries from helmeted motorized two-wheelers between 1996 and 2003 recorded in France. The extremities were the most often injuries and whatever the body segments, head-on scenario accounted for more than $30 \%$ of injuries. Considering AIS4+ victims, head injuries appeared for about $45 \%$ and thorax for about $50 \%$.

In the Cherta Ballester et al study [8] as well as Piantini et al [18], the leading accident scenario was the head-on-side collisions when COST 327 [17] reports that oblique-on-side was the most frequent accident scenario. Regarding to these previous studies, the choice of the accident scenarios was considered as representative.

Focusing to the head, the extraction of impact conditions shows that the location of the impacts is often on face and front area when impacting vehicle whereas they are more spread when impacting ground. Figure 11 shows the cumulative of occurrence in terms of head, thorax abdomen and pelvis impact velocity against the vehicle and the ground. It is observed that the tangential component is higher than the normal component in at least $50 \%$ of the simulations when the head impacts the vehicle. This observation gives further illustrates the need of oblique helmet testing. The mean value of the normal head impact velocity is of $7.4 \pm 3.2 \mathrm{~m} / \mathrm{s}$ on the vehicle contact and mainly located at chin area, as illustrated in Figure 7. For $75 \%$ of the simulation, the normal head impact velocity is over $6 \mathrm{~m} / \mathrm{s}$. When impacting the ground, the head impact velocity is lower with a normal component which doesn't exceed $4.4 \mathrm{~m} / \mathrm{s}$ for $75 \%$ of the simulations. As long as the head is concerned, these results are in accordance with the simulation of realworld accidents reported by Bourdet et al [16] in the context of 
new helmet test method development. They are also in line with helmet standards as long as the linear impact is considered.
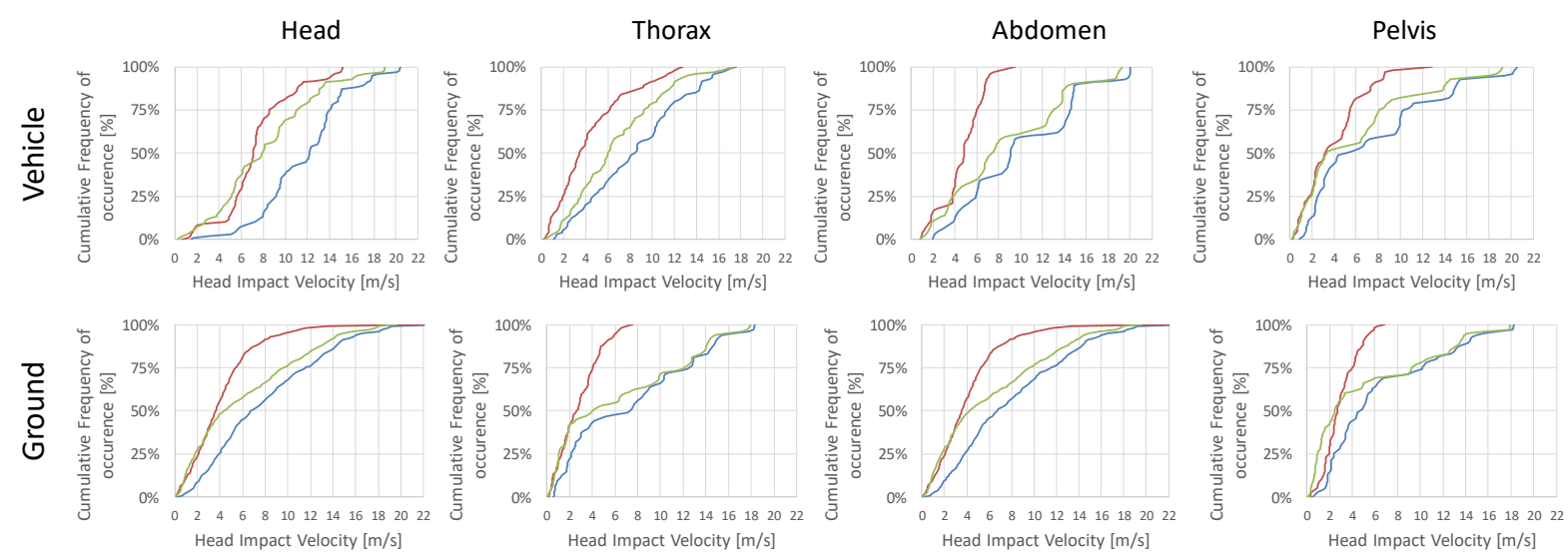

Figure 11. Cumulative frequency of occurrence for the impact speed against the vehicle (on top) and the ground (on bottom) for different body parts: (bue) resultant velocity, (red) normal velocity, (green) tangential velocity.

For the thorax, abdomen and pelvis parts, $75 \%$ of the impacts leads to a normal impact speed between 2 to $6 \mathrm{~m} / \mathrm{s}$ when impacting the car. Currently the standard test for shock absorption of chest protector, NF EN 1621-3, proposes an impact test of a $5 \mathrm{~kg}$ mass with an impact energy of $50 \mathrm{~J}$, which corresponds to an impact velocity of about $4.4 \mathrm{~m} / \mathrm{s}$ and only force is recorded which must not exceed $20 \mathrm{kN}$. Nwadiaro et al [21] as well as Kraus et al [22] observed that chest and abdominal injuries are commonly seen in fatal motorcycle accidents with fractures as well as soft tissue and vascular injuries. In 2017, Faduyle et al [23] reported pattern of injuries in fatal motorcycle accidents. The authors observed that rib fracture and lung laceration appeared for $46.7 \%$ and $17.4 \%$ respectively with regard to thorax injuries. Lung injuries are usually caused by lacerations due to broken ribs but also compression of the thoracic cavity. Moreover, the airbag protective system, the activation time must be less than $200 \mathrm{~ms}$ defining in EN 1621-4. But as observed from the simulation and plotted in Figure 10, thorax contacts the car in less than 80 ms for more than $75 \%$ of the simulations. This was confirmed by Serre et al in 2012 [6] and more recently by Cherta ballester et al in 2019 [8].

The main limitation of this study is that the range of postures is non-exhaustive and could gather more possible configurations. Nevertheless, it constitutes a representative range of realistic configurations, which permit to involve a large number of kinematics. Another limitation is the use of multibody approach which propose a simplification of the modelling compare to finite elements simulations, as the contact force curves used in the present study were obtained by rigid impactor against car parts. Finally, limitations also exist at human body modelling level where a state of the art model was applied as for pedestrian or bicycle accident simulation. Indeed, the pedestrian model used for the present study is validated in pedestrian configuration and not in the specific use of motorcyclist. It is possible that in real life the human would turn its head and other body parts to avoid facial impact or have other avoidance reflexes. The hypothesis that the reaction time is longer than $100 \mathrm{~ms}$ is considered in this study, as the first contact appears at $80 \mathrm{~ms}$.

The aim of this study is to evaluate the impact conditions of body parts in terms of impact velocity and location. It is not to evaluate the injury risk as multibody simulation is not the state-of-the-art tool for that. A future work will consist in implementing the body part impact conditions in finite elements of models in order to evaluate the injury risk.

\section{Conclusion:}


This study presents a parametric study based on multi-body simulation of motorcyclist's kinematic in case of motorcycle versus car accident. Eight accident scenarios were chosen to simulate collisions of the front part of the motorcycle against several points of the car. Three Size of the rider and two type of PTW (sport motorcycle and scooter) as well as two PTW initial velocity $(50 \mathrm{~km} / \mathrm{h}$ and $70 \mathrm{~km} / \mathrm{h}$ ) have permit to simulate and analyse a total of 96 accident scenarios. It reports the impact velocity per body segment for a large range of impact conditions, both against car and road surface and permits to establish realistic impact conditions dedicated to the testing of protection systems. Further, the timing of impact is computed providing essential information for the deployment of active protection systems. Results show that for over $50 \%$ of the simulations, the impact velocities of the whole body exceed $8 \mathrm{~m} / \mathrm{s}$ when impacting the vehicle and $4 \mathrm{~m} / \mathrm{s}$ at the time of road impact, when the PTW impact a city car with an initial velocity in the range of $50-70 \mathrm{~km} / \mathrm{h}$. It is for the lateral impact configuration that the head impacts the vehicle most often with a speed exceeding $7.5 \mathrm{~m} / \mathrm{s}$, when thorax, abdomen and pelvis are the most exposed segments for the other impact configurations, with impact velocities being in the range of 10 to $15 \mathrm{~m} / \mathrm{s}$. Changes in motorcyclist's BMI leads to minor influence on the impact velocities of the different body segments, especially for the first impact. As expected, body impact speed increases with the speed of the motorcycle, for both, the first and the second impacts. To the authors knowledge it is the first time that a detailed parametric study focuses on the impact velocity of the different body segments for the first and second impact, in a large range of motorcycle to car crash configurations and it is expected that this information will contribute to the development of test methods dedicated to passive and active protection systems.

\section{Acknowledgements}

This work is part of the "SECU2RM" project partly funded by the French Road Safety Foundation.

\section{References}

[1] « Urban Road Safety | ETSC ». https://etsc.eu/urban-road-safety/ (consulté le oct. 21, 2019).

[2] " ONISR: La Sécurité Routière en France. Bilan de l'accidentalité de l'année 2016. », Paris, 2017. Consulté le: oct. 21, 2019. [En ligne]. Disponible sur:

https://scholar.google.com/scholar_lookup?title=La\%20s\%C3\%A9curit\%C3\%A9\%20routi\%C3\%A8 re\%20en\%20France\&author=ONISR\&publication_year=2017.

[3] D. Otte, T. Facius, et S. Brand, « Serious injuries in the traffic accident situation: definition, importance and orientation for countermeasures based on a representative sample of in-depthaccident-cases in Germany ", Int. J. Crashworthiness, vol. 23, n 1, p. 18-31, janv. 2018, doi: 10.1080/13588265.2017.1301694.

[4] J. A. Newman, « The Biomechanics of Head Trauma and the Development of the Modern Helmet. How Far Have We Really Come? ", in Proceedings of the IRCOBI Conference, Prague, Czech Republic, 2005, p. 10.

[5] C. D. Rogers, G. Pagliarello, B. A. McLellan, et W. R. Nelson, « Mechanism of injury influences the pattern of injuries sustained by patients involved in vehicular trauma. - PubMed - NCBI », Canadian Journal of Surgery, p. 283-286, juin 1991.

[6] T. Serre, C. Masson, C. Perrin, J.-L. Martin, A. Moskal, et M. Llari, « The motorcyclist impact against a light vehicle: Epidemiological, accidentological and biomechanic analysis ", Accid. Anal. Prev., vol. 49, p. 223-228, nov. 2012, doi: 10.1016/j.aap.2012.08.013.

[7] S. Piantini et al., "Potential head injury mitigation of M-AEB in real-world motorcycle crashes", Int. J. Crashworthiness, p. 1-11, juin 2019, doi: 10.1080/13588265.2019.1626531.

[8] O. Cherta Ballester et al., "Analysis of trunk impact conditions in motorcycle road accidents based on epidemiological, accidentological data and multibody simulations ", Accid. Anal. Prev., vol. 127, p. 223-230, juin 2019, doi: 10.1016/j.aap.2019.03.006. 
[9] L. D. Baughman, « Development of an Interactive Computer Program to Produce Body Description Data »:, Defense Technical Information Center, Fort Belvoir, VA, juill. 1983. doi: 10.21236/ADA133720.

[10] H. Cheng, L. Obergefell, et A. Rizer, "Generator of Body Data (GEBOD) , Manual. ", SYSTEMS RESEARCH LABS INC DAYTON OH, mars 1994. Consulté le: juin 14, 2019. [En ligne]. Disponible sur: https://apps.dtic.mil/docs/citations/ADA289721.

[11] J. Van Hoof, R. De Lange, et J. S. H. M. Wismans, «Improving Pedestrian Safety Using Numerical Human Models ", Stapp Car Crash J., vol. 47, n October, p. 401-436, 2003.

[12] R. De Lange, R. Happee, et X. Liu, "Validation and application of human pedestrian models », in Madymo China user's meeting, 2005.

[13] E. J. Chen, J. Novakofski, W. K. Jenkins, et W. D. O'Brien, « Young's modulus measurements of soft tissues with application to elasticity imaging ", IEEE Trans. Ultrason. Ferroelectr. Freq. Control, vol. 43, n 1, p. 191-194, 1996.

[14] L. Martinez, L. J. Guerra, G. Ferichola, A. Garcia, et J. Yang, " Stiffness Corridors of the European fleet for pedestrian simulation », in Enhanced Safety Vehicles Conference, 2007.

[15] N. Bourdet, C. Deck, V. Tinard, et R. Willinger, « Behaviour of helmets during head impact in real accident cases of motorcyclists ", Int. J. Crashworthiness, vol. 17, n 1, p. 51-61, 2011, doi: 10.1080/13588265.2011.625676.

[16] N. Bourdet, S. Mojumder, S. Piantini, C. Deck, M. Pierini, et R. Willinger, « Proposal of a new motorcycle helmet test method for tangential impact ", p. 12, 2016.

[17] Bryan Chinn et al., " COST 327 Motorcycle Safety Helmets Final Report », European Cooperation in the Field of Scientific and Technical Research, 2001.

[18] S. Piantini et al., « Injury Analysis of Powered Two-Wheeler versus Other-Vehicle Urban Accidents », p. 14, 2016.

[19] R. Fredriksson et B. Sui, " Powered Two-Wheeler Accidents in Germany with Severe Injury Outcome - Accident Scenarios, Injury - Sources and Potential Countermeasures », p. 12, 2016.

[20] A. Moskal, J.-L. Martin, E. Lenguerrand, et B. Laumon, « INJURIES AMONG MOTORIZED TWOWHEELERS IN RELATION TO VEHICLE AND CRASH CHARACTERISTICS IN RHONE, FRANCE ", 20th Int. Tech. Conf. Enhanc. Saf. Veh., p. 10, juin 2007.

[21] H. Nwadiaro, I. Akpayak, K. Ekwe, et H. Shitta, « Motorcycle injuries in north-central Nigeria », Niger. J. Clin. Pract., vol. 14, n 2 2, p. 186, 2011, doi: 10.4103/1119-3077.84012.

[22] J. Kraus, C. Peek-Asa, et H. Cryer, " Incidence, Severity, and Patterns of Intrathoracic and Intraabdominal Injuries in Motorcycle Crashes ", J. Trauma Inj. Infect. Crit. Care, vol. 52, n 3, p. 548-553, mars 2002.

[23] F. Faduyile, F. Emiogun, S. Soyemi, O. Oyewole, U. Okeke, et O. Williams, "Pattern of Injuries in Fatal Motorcycle Accidents Seen in Lagos State University Teaching Hospital: An Autopsy-Based Study ", Open Access Maced. J. Med. Sci., vol. 5, n² 2, p. 112-116, févr. 2017, doi: 10.3889/oamjms.2017.025. 